\title{
OPEN Quantitative modeling of regular retinal microglia distribution
}

\author{
Yoshie Endo ${ }^{1}$, Daisuke Asanuma ${ }^{2}$, Shigeyuki Namiki ${ }^{2}$, Kei Sugiharaa ${ }^{1}$, Kenzo Hirose ${ }^{2}$, \\ Akiyoshi Uemura ${ }^{3}$, Yoshiaki Kubota ${ }^{4}$ \&akashi Miura ${ }^{1 \bowtie}$
}

Microglia are resident immune cells in the central nervous system, showing a regular distribution. Advancing microscopy and image processing techniques have contributed to elucidating microglia's morphology, dynamics, and distribution. However, the mechanism underlying the regular distribution of microglia remains to be elucidated. First, we quantitatively confirmed the regularity of the distribution pattern of microglial soma in the retina. Second, we formulated a mathematical model that includes factors that may influence regular distribution. Next, we experimentally quantified the model parameters (cell movement, process formation, and ATP dynamics). The resulting model simulation from the measured parameters showed that direct cell-cell contact is most important in generating regular cell spacing. Finally, we tried to specify the molecular pathway responsible for the repulsion between neighboring microglia.

Microglia are resident macrophages and show a regular distribution ${ }^{1}$ (Fig. 1A). Microglia cells have several physiological functions; control of neuronal cell production, neural migration, axonal growth, synaptogenesis $\mathrm{s}^{2,3}$ and angiogenesis ${ }^{4}$. Microglia cells also plays a role under pathological conditions; defense against infection, inflammation, trauma, ischemia, tumor, and neurodegeneration ${ }^{5}$. Microglia have two modes of action (Fig. 1B,C)in the healthy brain, they are inactive (resting) and become active during an immune response ${ }^{6}$. The resting and activated microglia have a distinct morphology and cell surface markers (Fig. 1B,C). Resting microglia have a small soma and elongated ramified processes extending and retracting continuously, surveying their microenvironment ${ }^{7}$. When microglia recognize a pathogen or other inflammatory stimulus, they rapidly become an active state, retract their processes and become efficient mobile effector cells. ATP mediates the chemotaxis toward the injured site. Injured cells release ATP, activating the microglial P2X and P2Y receptors. Extracellular ATP regulates microglia branch dynamics and mediates microglial movement toward the injury ${ }^{8-10}$. Local injection of ATP can mimic this immediate chemotactic response $\mathrm{e}^{11}$.

Microglia are derived from primitive hematopoiesis progenitors in the fetal yolk sac during the early embryonic stage ${ }^{12,13}$. They migrate into all CNS regions, disseminate through the brain parenchyma, and acquire a specific ramified morphological phenotype ${ }^{14}$. Quail microglial precursors enter the retina from the optic nerve head and migrate in a central to peripheral direction. ATP plays a role in the entry and migration of microglial precursors into the developing quail retina. The mechanism for microglial colonization of the CNS appears to be a conserved process across vertebrates ${ }^{15}$. Other adult tissue-resident macrophages are Kupffer cells in the liver, Langerhans cells in the epidermis, and alveolar macrophages in the lung ${ }^{16}$.

Advancing microscopy and image processing techniques have made the assessment of microglia morphology more feasible. Nimmerjahn et al. reported a highly active motile processes of resting microglial cells using in vivo two-photon imaging ${ }^{7}$. Davis et al. reported microglia density, nearest neighbor distance, regularity index, and phenotypes such as soma size and roundness of the mouse retina ${ }^{17}$. However, the mechanism and the molecular pathway of the regular distribution are unclear.

In the present study, we tried to elucidate the mechanism of regular distribution formation using the mouse retina as a model system. Firstly, we quantified the retinal microglia distribution pattern and confirmed the pattern regularity. Next, we formulated a mathematical model that includes the known regulatory factors of microglial migration. To verify the models experimentally, we quantified the model parameters, reproduced the dynamics with numerical simulations, and tried to specify the molecular pathway responsible for the repulsion between neighboring microglia.

\footnotetext{
${ }^{1}$ Department of Anatomy and Cell Biology, Graduate School of Medical Sciences, Kyushu University, Fukuoka, Japan. 'Department of Pharmacology, Graduate School of Medicine, The University of Tokyo, Tokyo, Japan. ${ }^{3}$ Department of Retinal Vascular Biology, Nagoya City University Graduate School of Medical Sciences, Aichi, Japan. ${ }^{4}$ Department of Anatomy, Keio University School of Medicine, Tokyo, Japan. ${ }^{\square}$ email: miura_t@ anat1.med.kyushu-u.ac.jp
} 

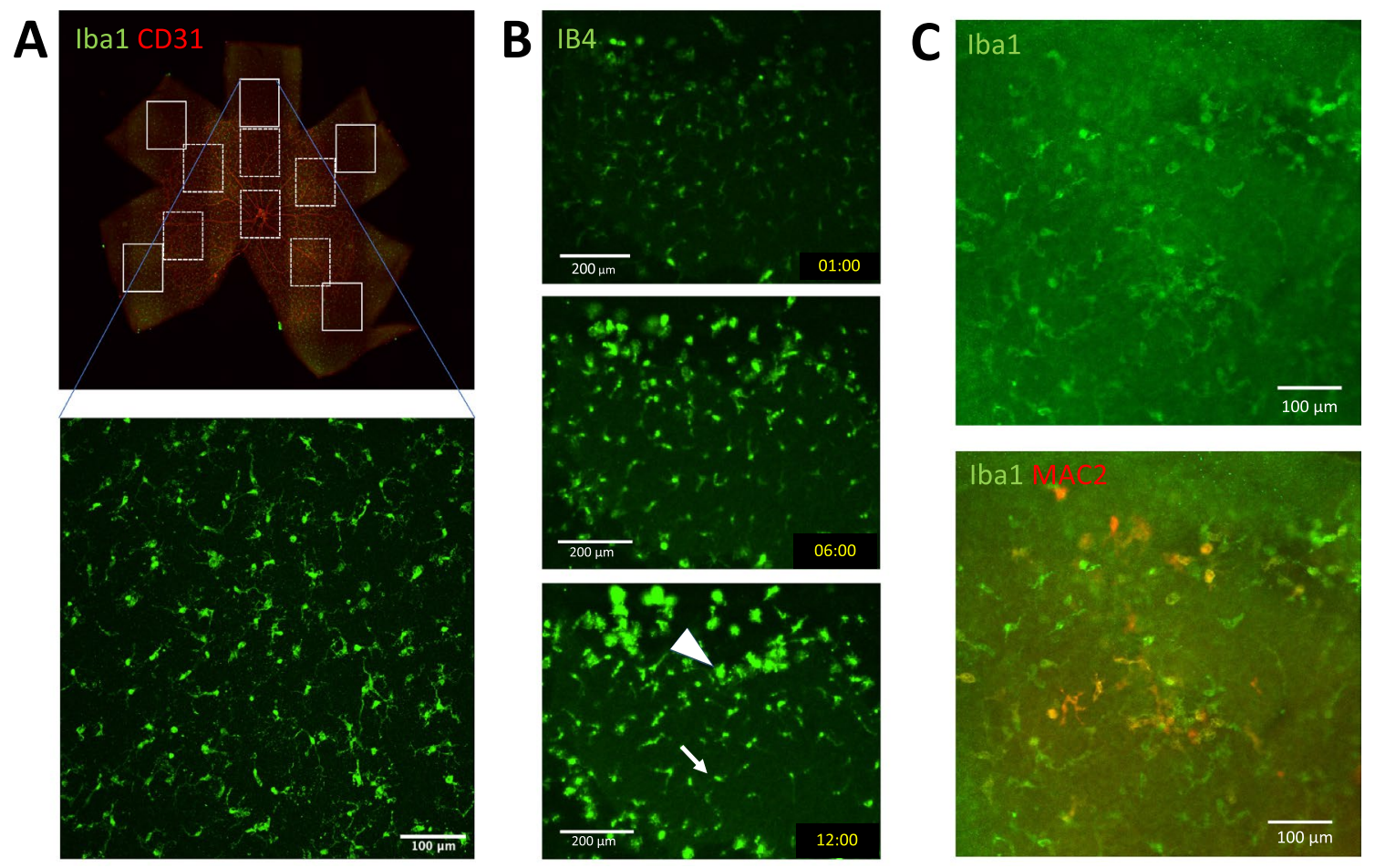

Figure 1. Microglia distribution and morphology. (A) Microglia in the peripheral avascular and the central vascular area of a P5 mouse retina. Boxes of the solid line represent the avascular areas, and those of the dashed line represent the vascular areas. (B) Observation of microglia in the organ culture. Microglia away from the cut edge remain resting microglia (arrow). Some of the resting microglia were converted to activated microglia (arrowhead) and migrated to the injured peripheral edge during a 12-h time-lapse assay of mouse retina organ culture. (C) Activated microglia around the wounded site, stained with MAC2 after the organ culture.

\section{Materials and methods}

All the methods described below were carried out in accordance with relevant guidelines and regulations.

Tissue preparation. We used postnatal day five (P5) wild-type mice (Slc: ICR strain) purchased from Japan SLC, Inc., Japan. We sacrificed the P5 mice by decapitation and isolated eyeballs from the orbit for organ culture. After removing eyelids and fat tissues, we made a small hole at the cornea center with a $26 \mathrm{G}$ needle. The sclera was gradually removed from the hole using fine forceps, and we isolated the retina in Hanks' Balanced Salt Solution (HBSS). We removed the lens, vitreous body, and vitelline arteries and prepared the retina fragment with fine forceps. All the animal experiments were approved by the Kyushu University animal experiment committee (A29-036-1). The study was carried out in compliance with the ARRIVE guidelines.

Immunohistochemistry. We performed immunohistochemistry (IHC) of whole-mount samples or tissue sections as previously described ${ }^{18}$. Eyes were fixed for $20 \mathrm{~min}$ in $4 \%$ paraformaldehyde (PFA) in phosphate-buffered saline and then dissected. Retinal cups were post-fixed for $30 \mathrm{~min}$ and then stained by a standard protocol.

Hamster anti-CD31 (1:1000; 2H8; Chemicon, Temecula, CA), MAC2 (CEDARLANE), and Iba1 (1:1000; WAKO, Osaka, Japan) were used as primary monoclonal antibody. For nuclear staining, we treated specimens with DAPI (Molecular Probes) or Hoechst 33342 (Dojindo).

Organ culture. We dissected P5 mouse retinas in HBSS(+). Retinal pieces were cultured on a cell culture insert with a $0.4 \mu \mathrm{m}$ pore diameter (Millicell PICM0RG50, Merck Millipore Ltd, Cork, Ireland) in DMEM/Ham's F-12 without Phenol Red (Nacalai Tesque, INC. Kyoto, Japan) supplemented with 10\% FBS and $1 \%$ antibiotics (Penicillin-Streptomycin Mixed Solution, Nacalai Tesque, INC. Kyoto, Japan). We added Ib4 lectin (1/1000, Invitrogen I21411) to stain microglia.

Reagents used in the organ culture experiments are: Phosphatidylinositol-specific Phospholipase $\mathrm{C}$ from Bacillus cereus (PI-PLC, $0.5 \mathrm{U} / \mathrm{ml}$, Sigma-Aldrich P5542), Recombinant Mouse sFRP-1 Protein (1 $\mu \mathrm{g} / \mathrm{ml}, \mathrm{R} \& \mathrm{D}$ Systems, MN9019-SF-025), Plexin-D1 Fc fragment (30 $\mu \mathrm{g} / \mathrm{ml})$, Alexa Fluor 647-ATP (5 $\mu$ M, Invitrogen A22362), and Clopidogrel (25 $\mu \mathrm{M}$, TOCRIS 249010).

Extracellular ATP dynamics. We quantified the ATP uptake and diffusion using Alexa Fluor 647-ATP. We added $5 \mu \mathrm{M}$ of the fluorescently labeled ATP to the culture medium of the P5 retina organ culture. After 1 $h$ of incubation, we observed the ATP diffusion using fluoresecence recovery after photobleaching (FRAP). The 


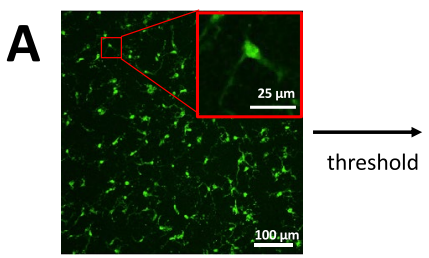

Z stack image
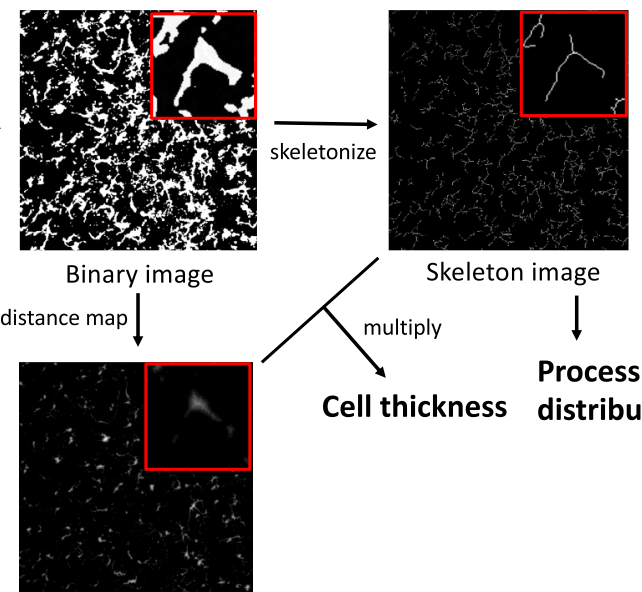

Skeleton image Cell thickness

Process distribution

find maxima

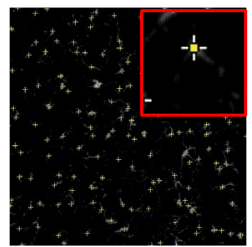

$\longrightarrow \mathrm{HSI}$, Cell density

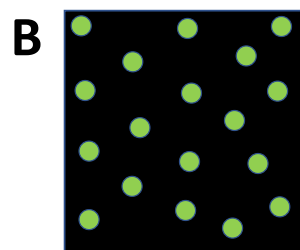

HSI < 1: regular

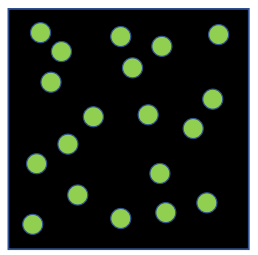

HSI = 1: random

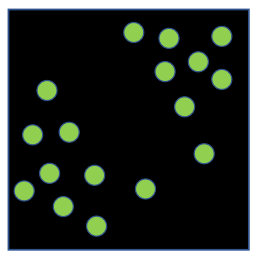

HSI > 1: aggregate

Soma coordinate

Figure 2. Image analysis. (A) Image processing for evaluation of microglia morphology (cell thickness and process distribution) and distribution (HSI and cell density). (B) Relationship between HSI and regularity of the microglia soma distribution.

diffusion coefficient is obtained according to Kang et al. ${ }^{19}$. ATP uptake by microglia was assessed by observation of the culture after $12 \mathrm{~h}$.

We observed the extracellular ATP concentration with ATPOS fluorescent sensor ${ }^{20,21}$. Dissected P5 retina cups were washed in pH 7.4 HEPES buffer solution (HBS. $25 \mathrm{mM}$ HEPES, $125 \mathrm{mM} \mathrm{NaCl}, 4 \mathrm{mM} \mathrm{KCl}, 2 \mathrm{mM}$ $\mathrm{CaCl}_{2}$ and $1 \mathrm{mM} \mathrm{MgCl}_{2}$ ), and incubated for 5 minutes at room temperature in $100 \mu \mathrm{l}$ of $0.33 \mu \mathrm{M}$ neuronalsurface-targeted ATPOS, a molecular complex of ATPOS with BoNT/C-Hc and Alexa Fluor 488 (Alexa488) labeled-streptavidin ${ }^{20,21}$ with 1/100 IB4-DyLight649 (DL-1208-5, Vector Laboratories). Then, the retina cups were washed with HBS $+0.1 \%$ BSA three times and transferred on the slide glass of a glass-bottom dish (3911-035-IN, Iwaki Glass). After supplementing with $500 \mu \mathrm{l}$ of DMEM/F-12 + $10 \%$ FBS, the optic cups were dissected, and the retina's anterior half was observed using a Nikon A1 confocal microscope. Extracellular ATP distribution was estimated using the Cy3/Alexa488 signal ratio ${ }^{20}$. We checked the fluorescence response of ATPOS in the organ culture by local application of $2 \mu \mathrm{l}$ of $10 \mathrm{mM}$ adenylyl-imidodiphosphate (AMP-PNP, Sigma-Aldrich A2647) , an ATP analog that is not degraded by ATPase, as a positive control. The final concentration of AMP-PNP should be $10 \mu \mathrm{M}$ in the culture medium. The AMP-PNP concentration was calculated using a molar absorption coefficient of $15,000 / \mathrm{M} / \mathrm{cm}$ at $260 \mathrm{~nm}$.

Image analysis. Evaluation of microglia morphology. We used customized image analysis methods to directly measure model parameters (Fig. 2). We acquired the confocal images $(30 \mu \mathrm{m} \mathrm{z}$-stack at $3 \mu \mathrm{m}$ intervals, Nikon A1, 20× objective) of the mouse retina. We performed the image processing using ImageJ (Fiji) software ${ }^{22}$ (Fig. 2A). First, we created the maximum intensity projections of $Z$ stacks, removed the noise by despeckling and smoothing, and obtained the binary images by thresholding. Since the skeleton length (microglia process) increased as the threshold values decreased, the threshold values were determined manually just before the skeleton length increased explosively $(35.2 \pm 0.84$, mean $\pm \mathrm{SE})$.

Next, we obtained the distance map images and the skeleton images from the binary images. We calculated the process distribution using the skeleton images. We multiplied the distance map image and the skeleton image for the evaluation of microglia thickness. The mean gray value of the multiplication result represents the mean thickness including the soma and the processes.

Evaluation of microglia distribution. The Hopkins-Skellam index ${ }^{23}$ (HSI) was adapted to analyze cell soma distribution (Fig. 2B). HSI is calculated from the following equation:

$$
H S I=\frac{\sum_{i=1}^{N} r_{1 i}{ }^{2}}{\sum_{i=1}^{N} r_{2 i}{ }^{2}} .
$$


$r_{1}$ is a distance from a point chosen at random to its nearest individual, $r_{2}$ is a distance from an individual chosen at random to its nearest individual, and $N$ is sample size. $H S I<1, H S I=1, H S I>1$ represents regular, random and aggregate patterns respectively (Fig. 2B).

Numerical simulations. All numerical simulationas are implemented using Mathematica (Wolfram Research). The source code of the numerical simulation is provided as an electronic supplementary material.

\section{Results}

Regular distribution of microglia in avascular and vascular area. We quantified the microglia soma distribution and the microglia morphology using image processing techniques (Fig. 2). We used the P5 mouse retina to observe microglia in both vascular and avascular areas since that microglia are associated with developing vasculature ${ }^{4}$. We expected that by comparing the distribution in these two regions, we could estimate the effect of the vasculature on the regularity of the pattern.

Microglia are already present in all regions of the embryonic day 11.5 (E11.5) mouse retina ${ }^{24}$, and angiogenesis starts at birth from the center but does not reach the retinal edges at $\mathrm{P} 5^{25}$. We observed 10 avascular (peripheral) and 10 vascular (around the center) areas in two retinae (Fig. 1A).

HSI of both avascular and vascular areas are smaller than $1(0.56 \pm 0.02$ vs. $0.53 \pm 0.02$, respectively), indicating that the microglia distribution pattern is regular (Fig. 3A,B). The microglia density is higher in the vascular area $\left(409 \pm 11\right.$ cells $/ \mathrm{mm}^{2}$ vs. $482 \pm 13$ cells $\left./ \mathrm{mm}^{2} ; P<0.001\right)$. The microglia thickness, including cells and processes, is higher $(3.7 \pm 0.5 \mu \mathrm{m}$ vs. $2.0 \pm 0.2 \mu \mathrm{m} ; P<0.001)$ and the average process length is shorter in the avascular area $(9.2 \pm 0.08 \mu \mathrm{m}$ vs. $9.5 \pm 0.1 \mu \mathrm{m} ; P<0.01)$, suggesting avascular (peripheral) microglia shows more amoeboid morphology. There was no significant difference in HSI, the number of processes per cell ( $7.4 \pm 0.8 \mathrm{vs}$. $7.0 \pm 0.6)$ and process length per cell $(68 \pm 7 \mu \mathrm{m}$ vs. $66 \pm 5 \mu \mathrm{m})$ between avascular and vascular areas (Fig. 3E,F).

A model of regular microglia distribution. In this section, we describe possible factors that may influence the regularity of the pattern and construct a model that incorporates the factors. The effects of these factors are later examined by experimental quantification. We focused on the avascular area of the P5 retina.

Factors involved in the microglia movement model. Since the critical factor for the observed regular microglia distribution is not clear, we listed up possible factors involved in the microglia distribution.

Initial distribution In some developmental systems, the cell arrangement pattern is regular from the beginning (like Turing patterns ${ }^{26}$ or Delta-Notch system ${ }^{27}$ ). In the case of microglia, they migrate from the fetal yolk sac to the retina during development ${ }^{13,15}$ and regular spacing is reported only at a late stage of development ${ }^{1}$. In addition, the microglial depletion experiment showed that newly formed microglia at first shows the random distribution and later becomes regular ${ }^{28}$. Thus, we assume that microglia initial distribution is random.

Random cell movement We observed random cell movement in microglia in organ culture (Fig. 4D). The cells show persistent random walk, which may interfere with regular cell distribution.

Chemotaxis toward ATP It is well known that ATP is a major chemoattractant of microglia ${ }^{8-10}$, which should influence the cell distribution.

ATP uptake Pinocytosis of microglia has been reported previously ${ }^{29}$. We presumed that if ATP uptake by microglia results in a local decrease of ATP around each microglia cell, other microglia cells move away due to the local ATP gradient. A similar mechanism was observed in the mutual repulsion of lung epithelial buds ${ }^{30}$.

Movement by cell-cell contact We hypothesized that cell-cell repulsion by direct contact plays a role in establishing the regular distribution of microglia. Although the repulsion by direct contact is not reported in microglia, some cells do repel each other by direct contact (contact inhibition of locomotion, CIL).

The model. We propose a model that includes all the factors described in the previous subsection as follows:

$$
\begin{gathered}
\frac{d \boldsymbol{r}_{i}}{d t}=\left.c \nabla a\right|_{\boldsymbol{r}=\boldsymbol{r}_{i}}-\sum_{i \neq j} f\left(\left|\boldsymbol{r}_{j}-\boldsymbol{r}_{i}\right|\right) \frac{\boldsymbol{r}_{j}-\boldsymbol{r}_{i}}{\left|\boldsymbol{r}_{j}-\boldsymbol{r}_{i}\right|}+\boldsymbol{v}_{i} \\
\frac{d \boldsymbol{v}_{i}}{d t}=\boldsymbol{\eta}(i, t) \\
\frac{\partial a}{\partial t}=p-h a-b \sum_{i=1}^{n} \delta\left(\boldsymbol{r}_{i}\right)+d_{a} \Delta a .
\end{gathered}
$$

(2) defines the cell movement; $\boldsymbol{r}_{i}$ represents the location of the $i$ th microglia cell and $a$ is the ATP distribution. $c$ is ATP chemotactic coefficient and $f(r)$ is repulsion function (Fig. 7A). When $\left|\boldsymbol{r}_{j}-\boldsymbol{r}_{i}\right|$ is longer than repulsive radius $(\sigma), f\left(\left|\boldsymbol{r}_{j}-\boldsymbol{r}_{i}\right|\right)=0$. When $\left|\boldsymbol{r}_{j}-\boldsymbol{r}_{i}\right|$ is shorter than $\sigma, f\left(\left|\boldsymbol{r}_{j}-\boldsymbol{r}_{i}\right|\right)=k\left(\sigma-\left|\boldsymbol{r}_{j}-\boldsymbol{r}_{i}\right|\right) ; k$ is microglia repulsive strength coefficient. The function $f(r)$ mimics that microglia repel each other only when they are close.

(3) implements the persistent random walk. The $i$ th cell moves at speed $v_{i}=\left|\boldsymbol{v}_{i}\right|$. The cell changes the direction of movement at average interval $\tau$ (persistence), which is implemented by the stochastic term $\eta(i, t)$.

(4) describes the dynamics of ATP concentration; $p$ is ATP production rate, $h$ is ATP decay coefficient, $b$ is ATP uptake rate, and $d_{a}$ is ATP diffusion coefficient. Microglia cells move according to ATP concentration and internalize ATP (Fig. 6). ATP is generated in the whole domain $(p)$, decay $(h a)$ and diffuse passively $\left(d_{a} \Delta a\right)$. 
A

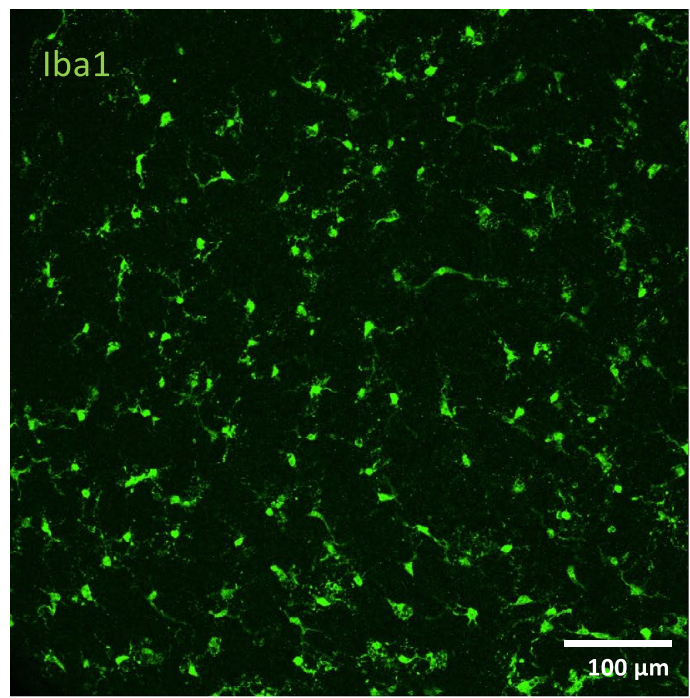

avascular area

B

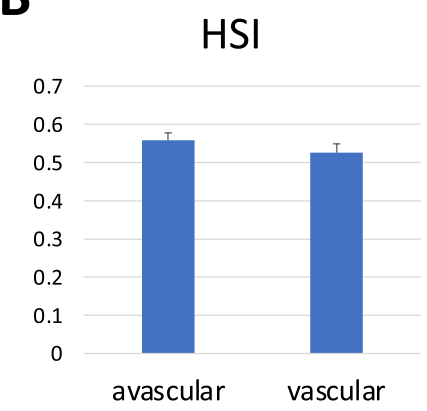

E

Number of processes per cell

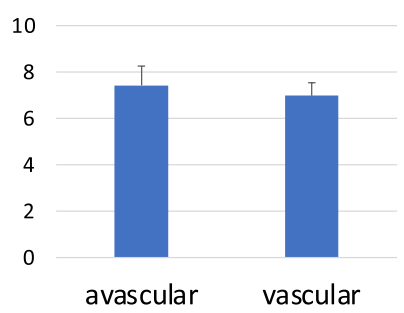

C

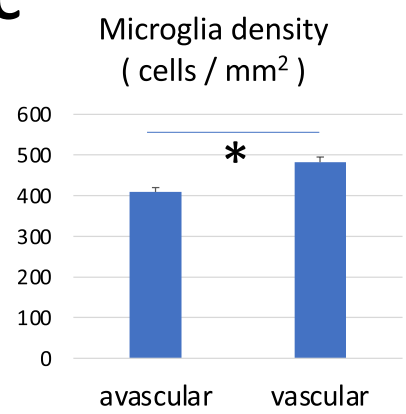

$\mathbf{F}$
Process length per cell $(\mu \mathrm{m} /$ cell )

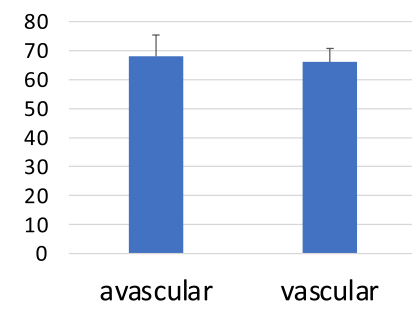

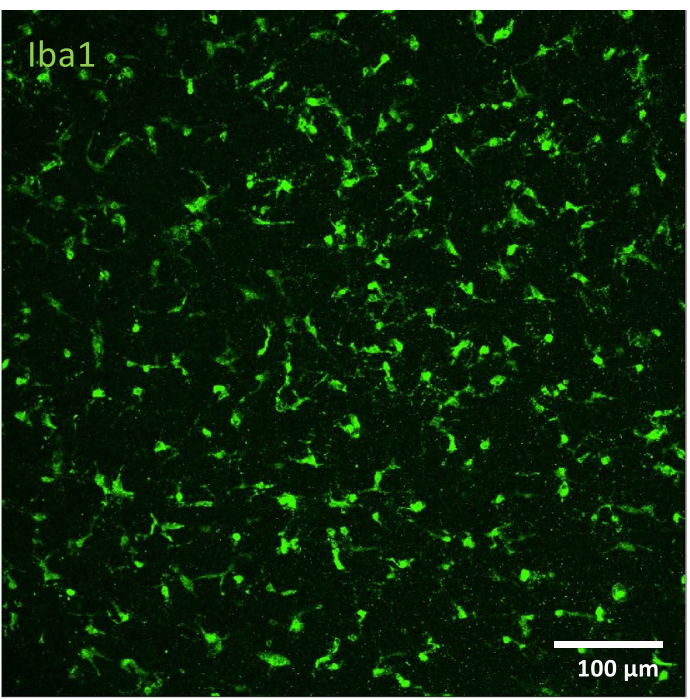

vascular area
D

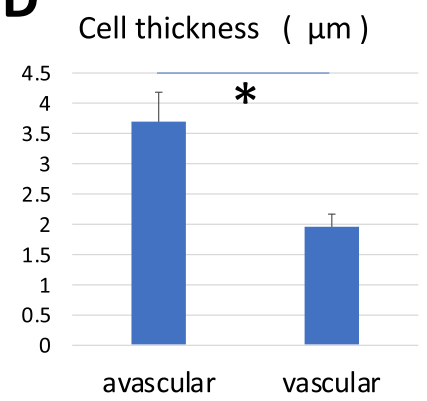

G

Average process length $(\mu \mathrm{m})$

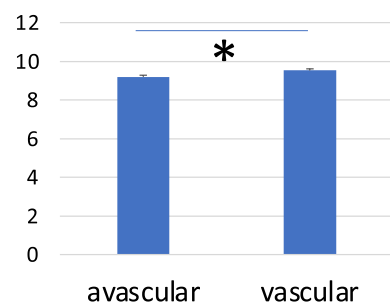

Figure 3. Quantification of Microglia distribution. (A) Microglia in the avascular and vascular area. (B-G) Quantification of the microglia distribution. (B) There was no significant difference in HSI. (C) Microglia density was higher in the vascular area. (D) Cell thickness was lower in the vascular area. (E) The number of processes per cell was not different. (F) Process length per cell was not different. (G) The average process length was longer in the vascular area. We used Student's $t$-test $(* p<0.05)$. All data are presented as mean \pm SE.

Quantification of the model parameters. Dynamics of microglial soma in organ culture. To quantify the dynamics of microglia, we observed microglia in the retinal organ culture. The cutting edge of the retina explants acts as a wound, and the activated microglial cells, which have amoeboid morphology, accumulated at the cut edges and accidentally damaged sites quickly (Fig. 1B,C). Currently, we could maintain the tissue only for $12 \mathrm{~h}$, which is not long enough to observe the disappearance of accumulation. In this study, we concentrated on the un-wounded region far from the cut edge of the explants.

We found that microglia move randomly and appear to repel neighbors when they get closer (Fig. 4A). We tracked the microglia migration (Fig. 4B), and analyzed the tracks that are longer than 50 frames (100 min). We found that most microglia migrate a short distance $\left(\mathrm{MSD} \approx 100 \mu \mathrm{m}^{2} / 100 \mathrm{~min}\right.$, Fig. $\left.4 \mathrm{C}\right)$. A part of the microglia migrated a long distance, which may be activated microglia because of the tissue damage by the dissection of the cultured retinas. We calculated the average of mean square displacement (MSD) with passage time (Fig. 4D); 

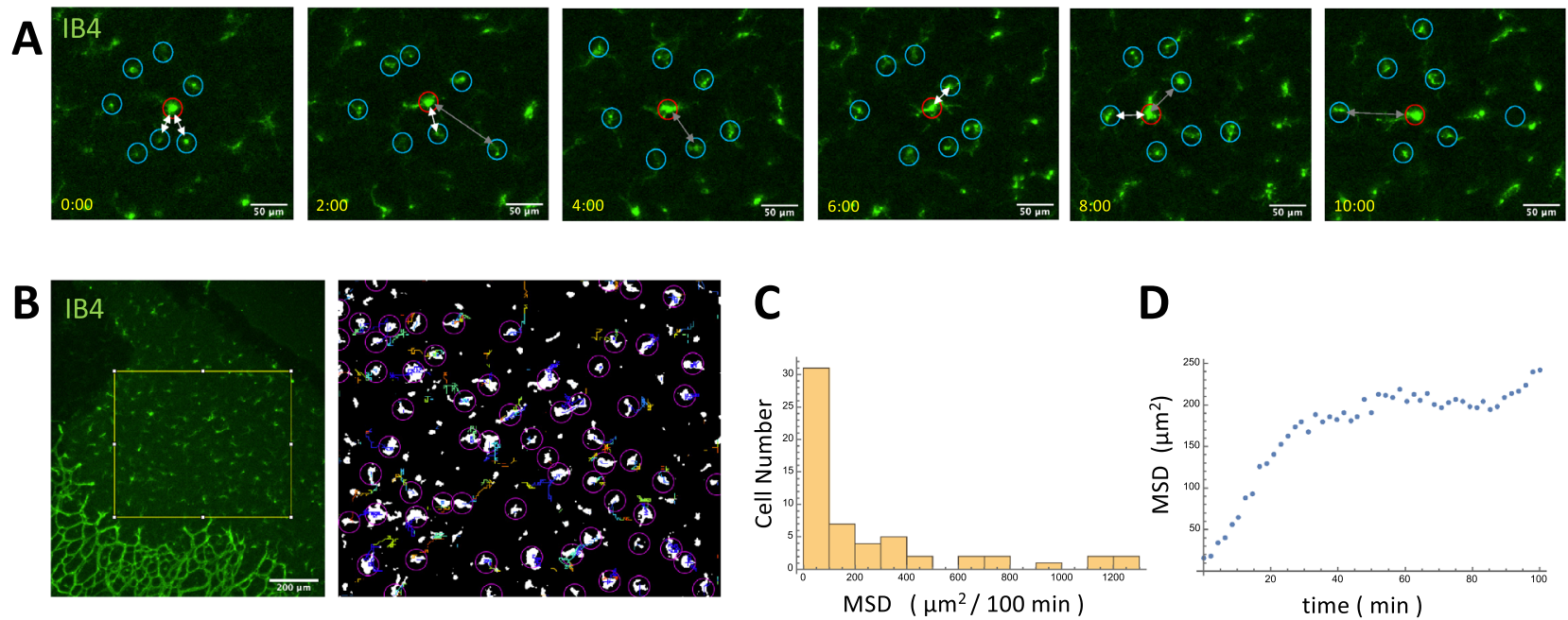

Figure 4. Dynamics of microglial soma in organ culture. (A) Microglia (red circle) moving randomly and repelling surrounding other microglia (blue circles) tracked for $10 \mathrm{~h}$. White arrows represent the pairs of microglia close to each other, and gray arrows represent the pairs of microglia that move away after approaching. (B) We tracked the microglia migration inside the yellow square in the left panel for $12 \mathrm{~h}$. The right panel shows that white regions representing each cell's first position and color lines representing each cell's 12 -h trajectory.

(C) The Histogram of MSD. We chose trajectories we could track for 50 frames (100 min, $\mathrm{n}=58$ ). (D) The mean MSD reached a plateau after $40 \mathrm{~min}$.

the MSD showed a linear increase initially but reached a plateau after 40 min., indicating that the microglia migration area is limited.

We obtained persistent random walk parameters from the diffusion coefficient (=MSD/time) and average speed from initial linear part of the MSD plot (Fig. 4D). Diffusion coefficient $\left(d_{u}\right)$ and average speed of the microglia $(v)$ were $d_{u}=6.0 \mu \mathrm{m}^{2} / \mathrm{min}$ and $v=0.88 \mu \mathrm{m} / \mathrm{min}$ respectively. Persistence $\tau$ was calculated by $d_{u} / v^{2}=7.7$ $\min$.

Dynamics of microglia process formation. An obvious candidate for the cell-cell repulsion mechanism is the microglia processes. We observed the dynamics of microglia process formation using organ culture. We found the processes showed slow growth and rapid collapse (Fig. 5A-C). We measured the average growth velocity of processes $g(0.36 \pm 0.04 \mu \mathrm{m} / \mathrm{min}$, mean $\pm \mathrm{SE}, \mathrm{n}=5)$ and the collapse probability $p(0.046 \pm 0.002 / \mathrm{min}$, mean \pm $\mathrm{SE}, \mathrm{n}=10)$. Based on this observation, we made a mathematical model of process distribution that predicts that microglia processes' length distribution obeys exponential distribution (Supporting Information).

We obtained the length distribution of microglia processes using image processing techniques (Fig. 2) and compared the result with model prediction. The experimental results of length distribution of the fixed specimen (Fig. 3) are represented by blue dots (Fig. 5D); the relationship between the log of process number and process length is linear $\left(y=7.6-0.14 x, R^{2}=0.96\right.$, avascular area vs. $y=7.7-0.14 x, R^{2}=0.97$, vascular area), which is consistent with model prediction. The values $\frac{p}{g}$ expected from the process dynamics model $(0.13)$ are consistent with the linear fitting slope of the actual process distribution (0.14).

Additionally, we measured the nearest neighbor distance (NND) in both the avascular and the vascular areas. Minimum NND are $9.6 \mu \mathrm{m}$ vs. $10 \mu \mathrm{m}$, and mean NND are $32 \pm 0.3 \mu \mathrm{m}$ vs. $30 \pm 0.2 \mu \mathrm{m}$ in avascular and vascular areas respectively (mean $\pm \mathrm{SE}, \mathrm{n}=1619, \mathrm{n}=1910$, Fig. 5E). Intuitively, microglia do not get closer beyond the average process length $(9.2 \pm 0.08 \mu \mathrm{m}$ vs. $9.5 \pm 0.1 \mu \mathrm{m}$, mean \pm SE, Fig. $3 \mathrm{G})$ because of the direct contact repulsion; therefore, a minimum NND smaller than the average process length does not exist.

ATP uptake, diffusion and extracellular distribution. We also quantified ATP dynamics in relation to microglia in mouse retina organ culture. We previously reported that the lung epithelium exerted a lateral inhibitory effect on the neighboring epithelium via depletion of fibroblast growth factor ${ }^{30}$. We presumed that microglia ingest ATP, decreased the neighborhood's concentration, and keep regular distribution. We observed microglia distribution and ATP concentration (Alexa Fluor ${ }^{\text {TM }} 647$ ATP) using the mouse retina organ culture. We found ATP colocalizes with the cell body of microglia (Fig. 6A), indicating that the uptake of ATP by the microglia does exist. We also measured the fluorescence change of microglia in organ culture with $5 \mu \mathrm{M}$ ATP-Alexa $(\mathrm{n}=15)$ for $12 \mathrm{~h}$ and obtained the uptake rate $b=9.5 \times 10^{-4} \mu \mathrm{M} \mathrm{min}{ }^{-1}$ per microglia cell.

Next, we quantified the diffusion of ATP in the cultured mouse retina using FRAP. Mouse P5 retina was incubated with $50 \mu \mathrm{M}$ ATP-Alexa647 for $1 \mathrm{~h}$ before the experiment. The dotted circle indicates the bleach spot. From the recovery curve of the fluorescence, we estimated that the diffusion coefficient of ATP is $180 \mu \mathrm{m}^{2} \mathrm{~min}^{-1}$. 

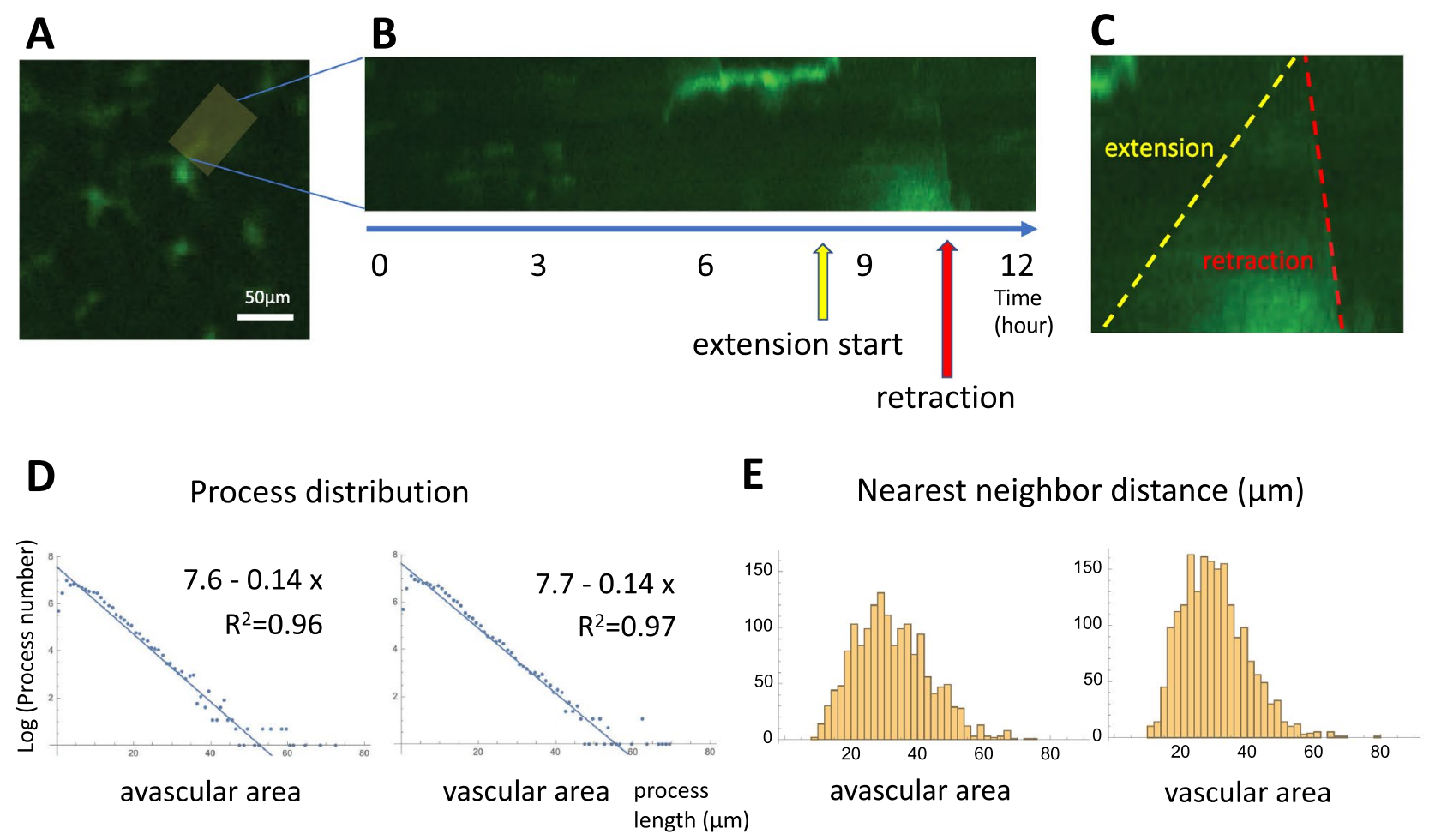

Figure 5. Dynamics of microglia process formation. (A) We obtained the kymograph of microglia process dynamics in the yellow area for $12 \mathrm{~h}$. Scale bar: $50 \mu \mathrm{m}$. (B) Microglia extended the process slowly and retracted quickly. (C) The process extension inclination is the yellow line, and the retraction is the red line. (D) The histogram of process distribution. (E) The histogram of NND.
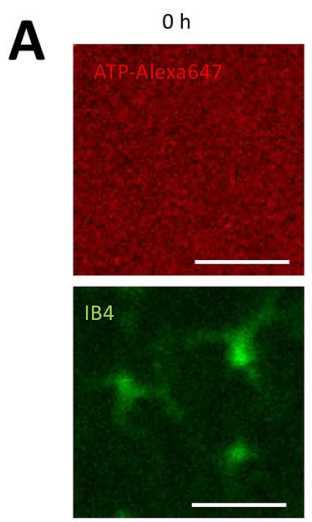

C

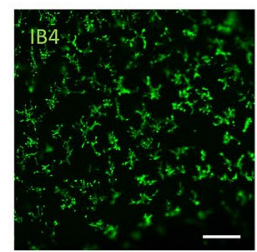

$6 \mathrm{~h}$
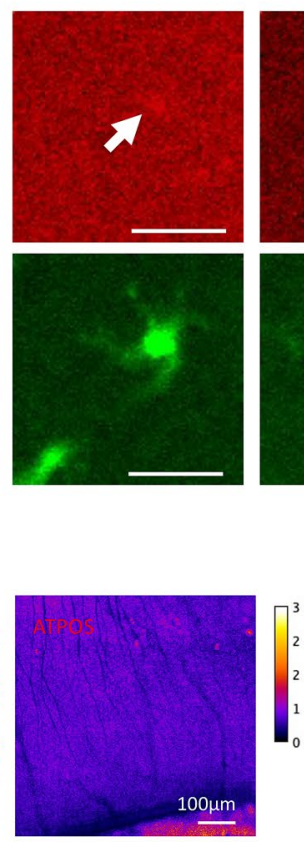

$12 \mathrm{~h}$
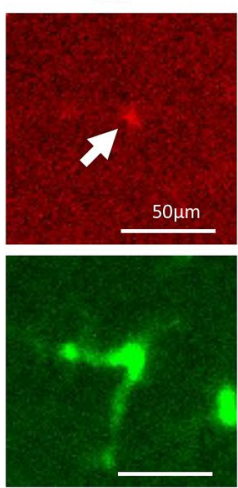

D

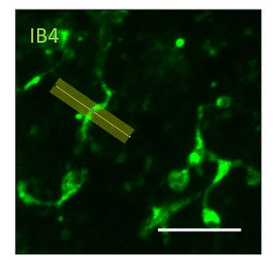

B
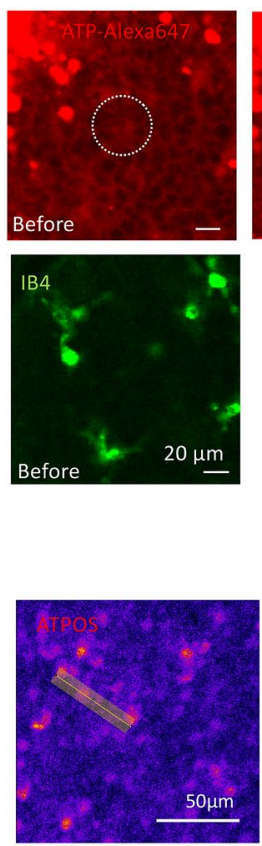
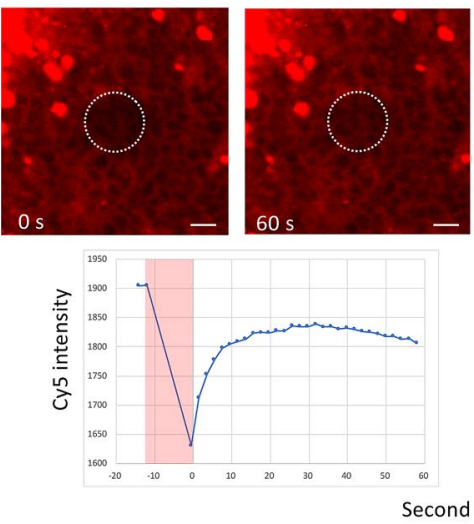

$\mathbf{E}$

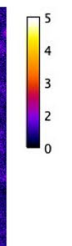

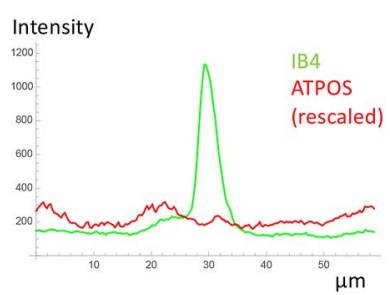

Figure 6. ATP dynamics in mouse retina organ culture. (A) ATP uptake of retinal microglia during $12 \mathrm{~h}$. (B) Measurement of the ATP diffusion coefficient by FRAP. After the sample was immersed with florescent ATP solution, a small region of the retina was photobleached, and the recovery was observed. (C-E) The extracellular distribution of ATP. (C) Low magnification view. (D) High magnification view. (E) Fluorescence intensity ratio around microglia. 


\begin{tabular}{|l|l|l|l|l|}
\hline Parameter & Description & Value & Unit & Source \\
\hline$c$ & ATP chemotactic coefficient & 18 & $\mu \mathrm{m}^{2} \mu \mathrm{M}^{-1} \mathrm{~min}^{-1}$ & Previous report $^{8}$ \\
\hline$\tau$ & Persistence & 7.7 & $\mathrm{~min}$ & Fig. 4 \\
\hline$v$ & Random cell migration speed & 0.88 & $\mu \mathrm{m} \mathrm{min}^{-1}$ & Fig. 4 \\
\hline$p$ & Extracellular ATP production rate & $1.7 \times 10^{-3}$ & $\mu \mathrm{M} \mathrm{min}$ & \\
\hline$h$ & ATP decay coefficient & 0.2 & $\mathrm{~min}^{-1}$ & Calculated from (4) \\
\hline$b$ & ATP uptake rate & $9.5 \times 10^{-4}$ & $\mu \mathrm{M} \mathrm{min}{ }^{-1}$ microglia $^{-1}$ & Fig. 6 \\
\hline$d_{a}$ & ATP diffusion coefficient & 180 & $\mu \mathrm{m}^{2} \mathrm{~min}^{-1}$ & Fig. 6 \\
\hline$\sigma$ & Microglia repulsive radius & 45 & $\mu \mathrm{m}^{32}$ \\
\hline$k$ & Repulsive strength coefficient & 0.1 & $\mathrm{~min}^{-1}$ & Previous report $\mathrm{t}^{17}$, Fig. 5 \\
\hline$a_{w}$ & ATP concentration at wound site & 25 & $\mu \mathrm{M}$ & Determined by simulation \\
\hline
\end{tabular}

Table 1. Simulation parameter values in the model.

We observed an immobile fraction in the recovery curve (Fig. 6B), indicating that the diffusion of a certain compartment of ATP is very slow ${ }^{31}$.

Finally, we observed the extracellular ATP distribution and microglia using ATPOS 20,21 (Fig. 6C-E). Extracellular ATP was detected using the Cy3-Alexa488 ratio, and the location of microglia was visualized using IB4DyLight649. We could not detect a local decrease in extracellular ATP distribution around the microglia (Fig. 6E).

Model parameters. We evaluated parameter values from the experiments described above to simulate the dynamics of microglia migration and ATP concentration (Table 1). Some parameters are estimated from previous work, which is described in Supporting information.

The numerical simulations of the model. We numerically confirmed whether the parameter set we obtained is sufficient to generate regular spacing.

Among the model parameters, the repulsion strength coefficient $k$ is the only parameter that the experimental observation cannot determine. We numerically obtained the effect of the different $k$ to the regular distribution of the microglia cells. $k$ works very efficiently in terms of the regular pattern formation, and small parameters like $k=0.1$ can generate a regular pattern (Fig. 7A). At first, we assumed that the depletion of ATP could also play a role, but $k=0$ simulation shows no regular distribution, indicating the effect of direct cell-cell repulsion may be the primary factor.

One concern about the parameter estimation and ATP effect is that the chemotactic coefficient $c$ may be underestimated because it is based on an in vitro experiment ${ }^{8}$. To rule out this possibility, we first observed what $c$ value can reproduce regular spacing without cell-cell repulsion $(k=0)$. We needed a very large chemotactic factor for the regular spacing $(c=20000)$ from the model simulation, which is 1000 times higher than the observed value (Fig. 7B). In addition, the original model parameter $(c=18)$ reproduced the accumulation of the microglia cells at the wounded site (Fig. 1B). Since the production rate of the ATP at the wound site is unknown, we set the concentration of the ATP at the wound site as the $1 / 300$ of the intracellular concentration (Fig. 7C, ${ }^{33}$ ). We observed the accumulation of the microglia cells at the wound site (Fig. 7D, red), indicating that the chemotactic coefficient $c$ is appropriate. The final ATP distribution and microglia cell distribution in the model are shown in Fig. 7E,F. We observed the decrease of ATP concentration at the microglia location, but the concentration decrease is very small (Fig. 7E), consistent with ATPOS observation (Fig. 6C-E). Finally, we estimated the order of $k$, which should represent the inverse of the time required for the repulsion to take effect. We estimated that the characteristic timescale for repulsion as $10 \mathrm{~min}$. $(k=0.1)$ and confirmed that the parameter set can reproduce regular spacing (Fig. 7F).

Screening molecular pathways for cell-cell interaction. Finally, we tried to specify the molecular pathway responsible for the direct contact repulsion or ATP. Since the mechanism of repulsion by cell-cell contact has not been described in microglia, we screened three pathways responsible for CIL: the ephrin-Eph pathway, the Wnt-planar cell polarity (PCP) pathway, and the Semaphorin pathway.

We confirmed Eph-ephrin, Wnt-PCP, and semaphorin pathway gene are expressed in mouse microglia using RefEx (Reference Expression dataset) ${ }^{34}$. We used phosphatidylinositol-specific phospholipase C (PI-PLC) which inhibits the EphA-ephrinA system, Secreted Frizzled Related Protein 1 (sFRP1) to block the Wnt-PCP pathway ${ }^{35}$, and Plexin-D1 Fc fragment to inhibit the semaphorin pathway.

We observed microglia distributions at $400 \mu \mathrm{m} \times 400 \mu \mathrm{m}$ in the avascular area of organ culture for $12 \mathrm{~h}$ (Fig. 8A), treated with PI-PLC, sFRP1, and Plexin-D1 Fc fragment assumed to inhibit microglia cell-cell repulsion. The HSI of the treated groups tends to be higher than the control (Fig. 8B), indicating that inhibitors of cell-cell repulsion interfere with regular microglia distribution. Microglia densities of the treated groups are lower than the control (Fig. 8C). We assume that microglia migrate at ease because of a lack of surrounding repulsion; thus, individual microglia migrate freely and into the peripheral damaged area. Therefore the cell density decreases within the observed field. 


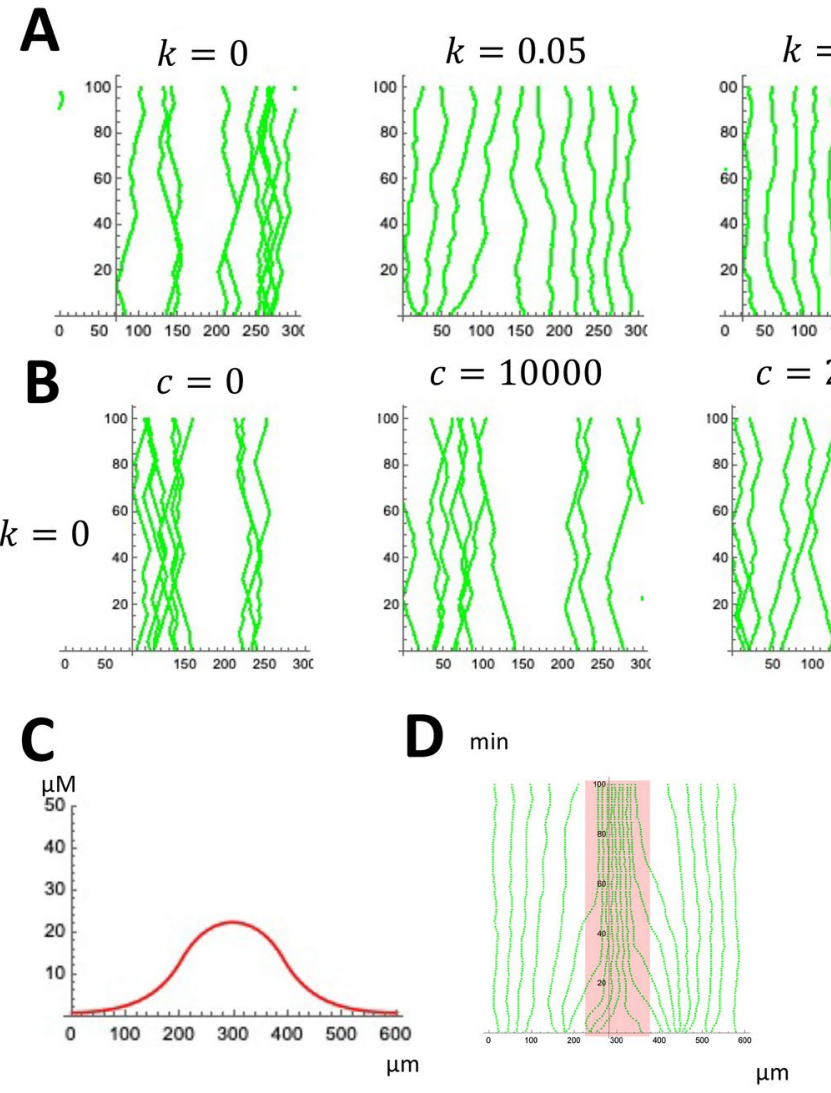

$k=0.1$

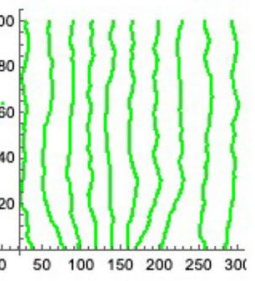

$c=20000$

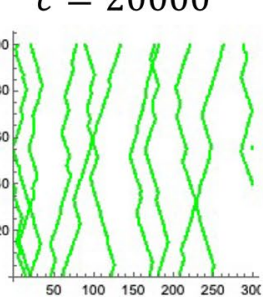

$k=0.15$

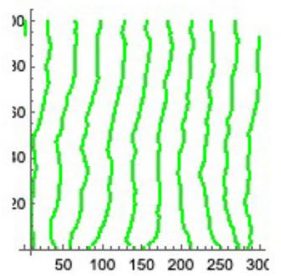

$c=30000$

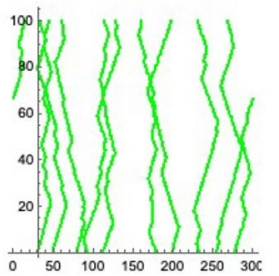

$k=0.2$

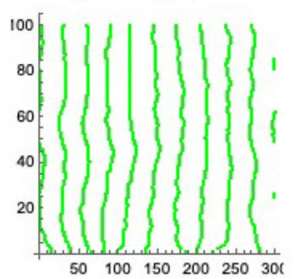

$c=40000$

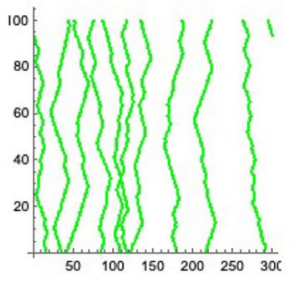

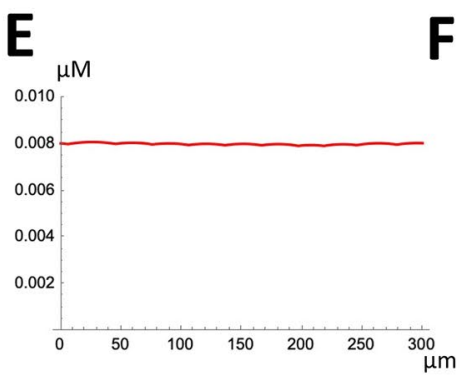

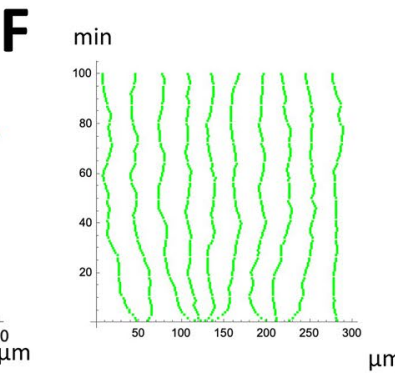

Figure 7. The model simulations. (A) Estimation of $k$ by numerical simulation. We set various $k$ values by numerical simulations, and found that very small $k$ can reproduce regular spacing. (B) Effect of chemotactic coefficient $c$ on regular pattern formation when repulsion does not work $(k=0)$. We needed unrealistically large $c$ to generate regular spacing. (C) Distribution of ATP at the wound site in the model. (D) Accumulation of microglia at the wound site in the model (Fig. 1B). (E) Distribution of ATP in the normal tissue in the model (Fig. 4C-E). (F) Microglia distribution of the quantitative model $(k=0.1)$. The cell distribution becomes regular as in Fig. 3.

Besides, we observed the microglia distribution treated with a saturating concentration of ATP-Alexa and clopidogrel (ATP P2Y receptor antagonist). The HSI of treated groups tends to be similar to that of the control group (Fig. 8D). Microglia densities of treated groups are higher than control (Fig. 8E). We assume that saturating amount of ATP or ATP inhibitor mask ATP gradient from the peripheral damaged area to the center of observed tissue; thus, treated microglia stay in the same position.

\section{Discussion}

The biological meaning of regular distribution. The physiological meaning of the regular distribution is not clear. The structure of resting microglia serves an immune surveillance function ${ }^{7}$. The regular distribution is assumed to be essential for the immune system and enables microglia to reach the injured site.

The regular distribution of microglia may play a role in the pattern formation of blood vessels. It is known that microglia influences angiogenesis ${ }^{36,37}$. Reduced number of microglia results in reduced vessel branching and density, while patterning was restored by intravitreal injection of exogeneous microglia ${ }^{38-40}$.

Models of microglia cell distribution. There are several theoretical studies concerning the distribution of microglia. Numahara et al. reported that the distribution of epidermal Langerhans cells is completely regular; the pattern of Voronoi divisions fits the territories hypothesized for the immuno-surveillance. They estimated a repulsive interaction between the Langerhans cells using the mathematical model ${ }^{41}$. However, the mechanism of the regular distribution of Langerhans cells is not specified.

Another model concentrates on aggregation formation of microglia around amyloid-beta plaques, not regular spacing $^{42}$. In this work, aggregation of microglia was reproduced using the Keller-Segel type chemotaxis model ${ }^{43}$.

Microglia process dynamics. Several features are known about the dynamics of process formation. Resting microglia extends the process to the injured site ${ }^{7}$ which is mediated by Gi-coupled P2Y12 ATP receptor and downstream Rac GTPase-driven actin polymerization ${ }^{8}$. Process retraction during the transition from resting to active microglia is mediated by the adenosine $\mathrm{A}_{2 A}$ receptor ${ }^{44}$. The speed of process extension and retraction were 
A

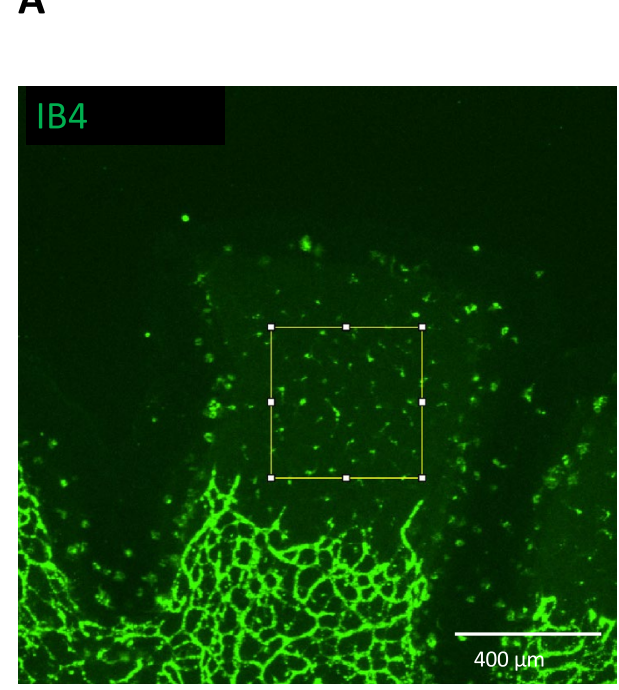

B 1.5

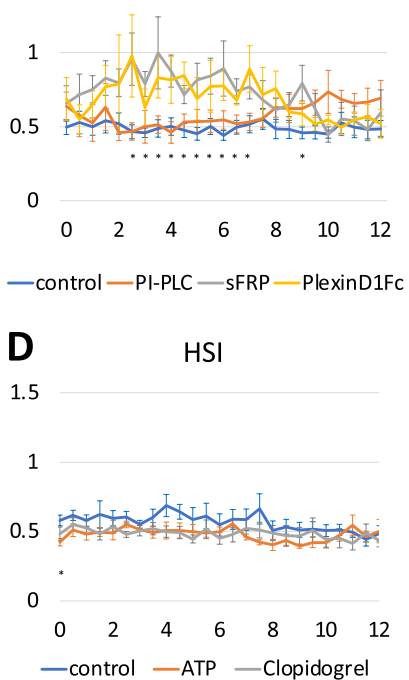

HSI
C Microglia density (cells/mm2)

400

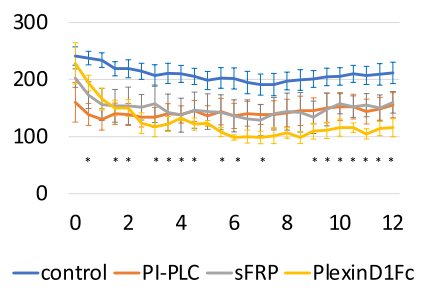

E Microglia density (cells/mm2)

400

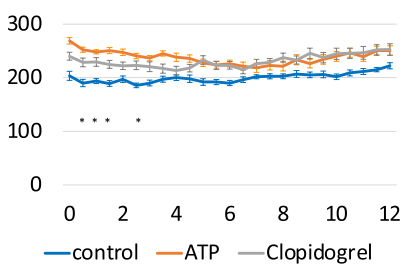

Figure 8. HSI and cell densities of microglia in organ culture. (A) Definition of measurement area. $400 \mu \mathrm{m} \times$ $400 \mu \mathrm{m}$ areas were measured. (B) HSI change by affecting repulsion mechanism $(k)$ (control: $n=7$, PI-PLC: $n=5$, sFRP: $n=5$, PlexinD1Fc: $n=4)$. (C) Cell densities change by affecting repulsion mechanism $(k)$. (D) HSI change by affecting initial ATP concentration (control: $n=7$, ATP: $n=8$, Clopidogrel: $n=7$ ). (E) Cell densities change by affecting initial ATP concentration. All data are represented as mean $\pm \mathrm{SE}$. * one-way ANOVA, $P<0.05$.

similar in the brain ${ }^{7}$, which is different from our observation in the retina (Fig. 5C). Resting microglia process movement is interspersed with a brief static period. The physiological meaning of this fixed period is not clear ${ }^{7}$.

We investigated the dynamics of the microglia process formation to obtain the characteristic length of repulsion. The mathematical model contains an advection term, representing constant growth of the processes, and degradation term, which represents the probabilistic process collapse. This model fits the experimentally observed process length distribution. This model is similar to our previous model ${ }^{45}$ and essentially equivalent to the McKendrick-von Foerster equation with a uniform death rate ${ }^{46}$. We found that microglia do not get closer beyond the average process length. We presume that microglia maintain distances between other microglia while extending and retracting the processes.

Contact inhibition of locomotion pathway. To our knowledge, there is no previous report describing the mechanism of microglia repulsion via contact by processes. Therefore we examined a general cell repulsion mechanism known as the contact inhibition of locomotion, initially described in the behavior of fibroblast cells ${ }^{47,48}$.

Three molecular pathways of CIL are known-the Eph-ephrin pathway ${ }^{49}$, the Wnt-PCP pathway ${ }^{49,50}$ and the Semaphorin pathway ${ }^{51}$. Eph and ephrin are membrane-bound receptors and ligands, respectively, and when Eph-expressing cells contact an ephrin-expressing cell, the cells repel each other. Ephrin-Eph signaling plays an essential role in cell segregation during development ${ }^{52,53}$. Noncanonical Wnts (e.g., Wnt4, Wnt5A, and Wnt11) activate $\mathrm{PCP}^{54}$ that is related to CIL. sFRP is one of the extracellular inhibitors of this pathway ${ }^{35}$. Semaphorins are secreted or transmembrane proteins that mediate repulsive axon guidance, immune cell regulation, and vascular growth and remodeling ${ }^{55}$. Semaphorins signal through plexins that recruit and regulate kinases and Rho-family GTPases to control cell motility ${ }^{56}$.

Application of the model to the other systems. This study concentrated on retinal microglia, but it may be possible to apply the model to other biological systems. Microglia cells in other CNS regions are obvious candidates. It has been reported that there is a regional difference of microglial cell density ${ }^{57-59}$. Cell density is lowest in the cerebellum, which may reflect stronger cell-cell repulsion activity. Differentially expressed genes (DEG) between microglia cells of different CNS regions have been reported ${ }^{60}$. We could not found DEG related to the known direct cell-cell repulsion pathway such as Eph-ephrin, Wnt-PCP, Semaphorin pathways (Supporting Information). Langerhans cells in the skin is another candidate ${ }^{61}$, although the observation of dynamics is more difficult in skin explant due to the stratified epithelium.

Cell-cell repulsion by direct contact in other systems. Although the mechanism of cell-cell repulsion in microglia has not been reported, previous works described the mechanism in other cell types. Mouse oligodendrocyte precursor cells (OPC) survey their local environment with motile filopodia and maintain unique 
territories through self-avoidance ${ }^{62}$. In Drosophila da sensory neurons, the mutual repulsion of dendrites is regulated by gene encoded in Dscam (Down syndrome cell adhesion molecule) locus ${ }^{63}$. PVD nociceptive neuron in C. elegans extends dendrites that do not cross each other. The axon guidance protein UNC-6/Netrin is required for this self-avoidance ${ }^{64}$. Two mouse retinal interneuron subtypes (starburst amacrine cells and horizontal cells) show regular distribution, and MEGF10 and MEGF11 are involved in this regular distribution ${ }^{65}$.

Conclusion. In the present study, we constructed a quantitative model to understand regular retinal microglia distribution mechanisms. We quantified the distribution pattern to confirm the regularity and formulated a model including major known factors to regulate microglial motility. Then we quantify the model parameters experimentally using the organ culture system. The model simulation showed that cell-cell repulsion by direct contact might be the significant factor for the formation of regularity. Possible applications to other biological systems are discussed.

Received: 12 July 2021; Accepted: 3 November 2021

Published online: 22 November 2021

\section{References}

1. Hume, D. A., Perry, V. H. \& Gordon, S. Immunohistochemical localization of a macrophage-specific antigen in developing mouse retina: Phagocytosis of dying neurons and differentiation of microglial cells to form a regular array in the plexiform layers. J. Cell Biol. 97, 253-257. https://doi.org/10.1083/jcb.97.1.253 (1983).

2. Konishi, H., Kiyama, H. \& Ueno, M. Dual functions of microglia in the formation and refinement of neural circuits during development. Int. J. Dev. Neurosci.https://doi.org/10.1016/j.ijdevneu.2018.09.009 (2018).

3. Hattori, Y. et al. Transient microglial absence assists postmigratory cortical neurons in proper differentiation. Nat. Commun. 11, 1631. https://doi.org/10.1038/s41467-020-15409-3 (2020).

4. Fantin, A. et al. Tissue macrophages act as cellular chaperones for vascular anastomosis downstream of VEGF-mediated endothelial tip cell induction. Blood 116, 829-840. https://doi.org/10.1182/blood-2009-12-257832 (2010).

5. Kreutzberg, G. W. Microglia: A sensor for pathological events in the CNS. Trends Neurosci. 19, 312-318. https://doi.org/10.1016/ 0166-2236(96)10049-7 (1996).

6. Kierdorf, K. \& Prinz, M. Factors regulating microglia activation. Front. Cell. Neurosci. 7, 1-8. https://doi.org/10.3389/fncel.2013. 00044 (2013).

7. Nimmerjahn, A., Kirchhoff, F. \& Helmchen, F. Resting microglial cells are highly dynamic surveillants of brain parenchyma in vivo. Neuroforum 11, 95-96. https://doi.org/10.1515/nf-2005-0304 (2005).

8. Honda, S. et al. Extracellular ATP or ADP induce chemotaxis of cultured microglia through G i/o-coupled P2Y receptors. J. Neurosci. 21, 1975-1982. https://doi.org/10.1523/JNEUROSCI.21-06-01975.2001 (2001).

9. Sasaki, Y. et al. Selective expression of Gi/o-coupled ATP receptor P2Y12 in microglia in rat brain. Glia 44, 242-250. https://doi. org/10.1002/glia.10293 (2003).

10. Madry, C. \& Attwell, D. Receptors, ion channels, and signaling mechanisms underlying Microglial dynamics. J. Biol. Chem. 290, 12443-12450. https://doi.org/10.1074/jbc.R115.637157 (2015).

11. Davalos, D. et al. ATP mediates rapid microglial response to local brain injury in vivo. Nat. Neurosci. 8, 752-758. https://doi.org/ $10.1038 / \mathrm{nn} 1472$ (2005).

12. Ginhoux, F. et al. Fate mapping analysis reveals that adult microglia derive from primitive macrophage. Science 701, 841-845. https://doi.org/10.1126/science.1194637 (2010).

13. Fan, Y., Xie, L. \& Chung, C. Y. Signaling pathways controlling microglia chemotaxis. Mol. Cells 40, 163-168. https://doi.org/10. 14348/molcells.2017.0011 (2017).

14. Helmut, K., Hanisch, U. K., Noda, M. \& Verkhratsky, A. Physiology of microglia. Physiol. Rev. 91, 461-553. https://doi.org/10. 1152/physrev.00011.2010(2011).

15. Martín-Estebané, M. et al. Onset of microglial entry into developing quail retina coincides with increased expression of active caspase-3 and is mediated by extracellular ATP and UDP. PLOS ONE 12, e0182450. https://doi.org/10.1371/journal.pone.01824 50 (2017).

16. GomezPerdiguero, E. et al. Tissue-resident macrophages originate from yolk-sac-derived erythro-myeloid progenitors. Nature 518, 547-551. https://doi.org/10.1038/nature13989 (2015).

17. Davis, B. M., Salinas-Navarro, M., Cordeiro, M. F., Moons, L. \& Groef, L. D. Characterizing microglia activation: A spatial statistics approach to maximize information extraction. Sci. Rep. 7, 1-12. https://doi.org/10.1038/s41598-017-01747-8 (2017).

18. Kubota, Y. et al. Isolation and function of mouse tissue resident vascular precursors marked by myelin protein zero. J. Exp. Med. 208, 949-960. https://doi.org/10.1084/jem.20102187 (2011).

19. Kang, M., Day, C. A., Kenworthy, A. K. \& DiBenedetto, E. Simplified equation to extract diffusion coefficients from confocal FRAP data. Traffic 13, 1589-1600. https://doi.org/10.1111/tra.12008 (2012).

20. Kitajima, N. et al. Real-time in vivo imaging of extracellular ATP in the brain with a hybrid-type fluorescent sensor. eLife 9, 1-18. https://doi.org/10.7554/eLife.57544 (2020).

21. Kitajima, N. et al. In vivo fluorescence imaging of extracellular ATP in the mouse cerebral cortex with a hybrid-type optical sensor. Bio-Protocol 11, 1-16. https://doi.org/10.21769/BioProtoc.4046 (2021).

22. Schindelin, J., Arganda-Carreras, I. \& Frise, E. Fiji: An open-source platform for biological-image analysis. Nat. Methods 9, 676-682. https://doi.org/10.1038/nmeth.2019 (2012).

23. Hopkins, B. \& Skellam, J. G. A new method for determining the type of distribution of plant individuals. Ann. Bot. 18, $213-227$. https://doi.org/10.1093/oxfordjournals.aob.a083391 (1954).

24. Santos, A. M., Calvente, R. \& Tassi, M. Embryonic and postnatal development of microglial cells in the mouse retina. J. Comp. Neurol. 506, 224-239. https://doi.org/10.1002/cne.21538 (2008).

25. Stahl, A. et al. The mouse retina as an angiogenesis model. Investig. Opthalmol. Vis. Sci. 51, 2813. https://doi.org/10.1167/iovs. 10-5176 (2010).

26. Kondo, S. \& Miura, T. Reaction-diffusion model as a framework for understanding biological pattern formation. Science 329, 1616-1620. https://doi.org/10.1126/science.1179047 (2010) (NIHMS150003).

27. Collier, J. R., Monk, N. A., Maini, P. K. \& Lewis, J. H. Pattern formation by lateral inhibition with feedback: A mathematical model of delta-notch intercellular signalling. J. Theor. Biol. 183, 429-446. https://doi.org/10.1006/jtbi.1996.0233 (1996) (0307072v1).

28. Coleman, L. G., Zou, J. \& Crews, F. T. Microglial depletion and repopulation in brain slice culture normalizes sensitized proinflammatory signaling. J. Neuroinflam. 17, 1-20. https://doi.org/10.1186/s12974-019-1678-y (2020). 
29. Li, H.-Q. et al. P2Y4 receptor-mediated pinocytosis contributes to amyloid beta-induced self-uptake by microglia. Mol. Cell. Biol. 33, 4282-4293. https://doi.org/10.1128/MCB.00544-13 (2013).

30. Miura, T. \& Shiota, K. Depletion of FGF acts as a lateral inhibitory factor in lung branching morphogenesis in vitro. Mech. Dev. 116, 29-38. https://doi.org/10.1016/S0925-4773(02)00132-6 (2002).

31. Kang, M., Day, C. A., Kenworthy, A. K. \& DiBenedetto, E. Simplified equation to extract diffusion coefficients from confocal FRAP data. Traffic 13, 1589-1600. https://doi.org/10.1111/tra.12008 (2012) (NIHMS150003).

32. Winkler, B. S. Relative inhibitory effects of ATP depletion, ouabain and calcium on retinal photoreceptors. Exp. Eye Res. 36, 581-594. https://doi.org/10.1016/0014-4835(83)90052-0 (1983).

33. Imamura, H. et al. Visualization of ATP levels inside single living cells with fluorescence resonance energy transfer-based genetically encoded indicators. Proc. Natl. Acad. Sci. 106, 15651-15656. https://doi.org/10.1073/pnas.0904764106 (2009).

34. Ono, H., Ogasawara, O., Okubo, K. \& Bono, H. RefEx, a reference gene expression dataset as a web tool for the functional analysis of genes. Sci. Datahttps://doi.org/10.1038/sdata.2017.105 (2017).

35. Kawano, Y. \& Kypta, R. Secreted antagonists of the Wnt signalling pathway. J. Cell Sci. 116, 2627-2634. https://doi.org/10.1242/ jcs.00623 (2003).

36. Penfold, P. L., Provis, J. M., Madigan, M. C., van Driel, D. \& Billson, F. A. Angiogenesis in normal human retinal development the involvement of astrocytes and macrophages. Graefes Arch. Clin. Exp. Ophthalmol. 228, 255-263. https://doi.org/10.1007/BF009 20031 (1990).

37. Chen, S. et al. CNS macrophages control neurovascular development via CD95L. Cell Rep. 19, 1378-1393. https://doi.org/10. 1016/j.celrep.2017.04.056 (2017).

38. Checchin, D., Sennlaub, F., Levavasseur, E., Leduc, M. \& Chemtob, S. Potential role of microglia in retinal blood vessel formation. Investig. Ophthalmol. Vis. Sci. 47, 3595-3602. https://doi.org/10.1167/iovs.05-1522 (2006).

39. Ritter, M. R. et al. Myeloid progenitors differentiate into microglia and promote vascular repair in a model of ischemic retinopathy. J. Clin. Investig. 116, 3266-3276. https://doi.org/10.1172/JCI29683 (2006).

40. Kubota, Y. et al. M-CSF inhibition selectively targets pathological angiogenesis and lymphangiogenesis. J. Exp. Med. 206, 10891102. https://doi.org/10.1084/jem.20081605 (2009).

41. Numahara, T., Tanemura, M., Numahara, K., Moriue, J. \& Shirahige, Y. Spatial statistics for epidermal langerhans cells-effects of protopic ointment $0.1 \%$ on the spatial distribution. Forma 24, 49-59 (2009).

42. Kinney, A. C. \& Swanson, E. R. Modeling aggregation of proliferating microglia in response to amyloid-beta in dementia. SPORA J. Biomath.https://doi.org/10.30707/SPORA3.1Kinney (2017).

43. Keller, E. F. \& Segel, L. A. Model for chemotaxis. J. Theor. Biol. 30, 225-234. https://doi.org/10.1016/0022-5193(71)90050-6 (1971).

44. Orr, A. G., Orr, A. L., Li, X.-J., Gross, R. E. \& Traynelis, S. F. Adenosine A(2A) receptor mediates microglial process retraction. Nat. Neurosci. 12, 872-878. https://doi.org/10.1038/nn.2341 (2009).

45. Sasaki, D. et al. Mathematical modeling for meshwork formation of endothelial cells in fibrin gels. J. Theor. Biol. 429, 95-104. https://doi.org/10.1016/j.jtbi.2017.06.012 (2017).

46. Keyfitz, B. \& Keyfitz, N. The McKendrick partial differential equation and its uses in epidemiology and population study. Math. Comput. Model. 26, 1-9. https://doi.org/10.1016/S0895-7177(97)00165-9 (1997).

47. Abercrombie, M. \& Heaysman, J. E. Observations on the social behaviour of cells in tissue culture. Exp. Cell Res. 5, 111-131. https:// doi.org/10.1016/0014-4827(53)90098-6 (1953).

48. Abercrombie, M. \& Heaysman, J. E. Observations on the social behaviour of cells in tissue culture. Exp. Cell Res. 6, 293-306. https:// doi.org/10.1016/0014-4827(54)90176-7 (1954).

49. Roycroft, A. \& Mayor, R. Molecular basis of contact inhibition of locomotion. Cell. Mol. Life Sci. 73, 1119-1130. https://doi.org/ 10.1007/s00018-015-2090-0 (2016).

50. Eszter, K. V., Antic, D. \& Jeffrey, D. A. Planar cell polarity signaling: The developing cell's compass. Cold Spring Harbor Persp. Biol. 1, 1-19. https://doi.org/10.1101/cshperspect.a002964 (2009).

51. Hung, R. J. \& Terman, J. R. Extracellular inhibitors, repellents, and semaphorin/plexin/MICAL-mediated actin filament disassembly. Cytoskeleton 68, 415-433. https://doi.org/10.1002/cm.20527 (2011).

52. Fagotto, F., Winklbauer, R. \& Rohani, N. Ephrin-Eph signaling in embryonic tissue separation. Cell Adhes. Migr. 8, 308-326. https:// doi.org/10.4161/19336918.2014.970028 (2014).

53. Nievergall, E., Lackmann, M. \& Janes, P. W. Eph-dependent cell-cell adhesion and segregation in development and cancer. Cell. Mol. Life Sci. 69, 1813-1842. https://doi.org/10.1007/s00018-011-0900-6 (2012).

54. Kohn, A. D. \& Moon, R. T. Wnt and calcium signaling: $\beta$-Catenin-independent pathways. Cell Calcium 38, 439-446. https://doi. org/10.1016/J.CECA.2005.06.022 (2005).

55. Alto, L. T. \& Terman, J. R. Semaphorins and their Signaling Mechanisms. In Methods in molecular biology (Clifton, N.J.), vol. 1493, 1-25. https://doi.org/10.1007/978-1-4939-6448-2_1 (Springer, 2017).

56. Kruger, R. P., Aurandt, J. \& Guan, K.-L. Semaphorins command cells to move. Nat. Rev. Mol. Cell Biol. 6, 789-800. https://doi.org/ $10.1038 / \mathrm{nrm} 1740$ (2005).

57. Lawson, L. J., Perry, V. H., Dri, P. \& Gordon, S. Heterogeneity in the distribution and morphology of microglia in the normal adult mouse brain. Neuroscience 39, 151-170. https://doi.org/10.1016/0306-4522(90)90229-W (1990).

58. Masuda, T., Sankowski, R., Staszewski, O. \& Prinz, M. Microglia heterogeneity in the single-cell era. Cell Rep. 30, 1271-1281. https://doi.org/10.1016/j.celrep.2020.01.010 (2020).

59. Tan, Y. L., Yuan, Y. \& Tian, L. Microglial regional heterogeneity and its role in the brain. Mol. Psychiat. 25, 351-367. https://doi. org/10.1038/s41380-019-0609-8 (2020).

60. Li, Q. et al. Developmental heterogeneity of microglia and brain myeloid cells revealed by deep single-cell RNA sequencing. Neuron 101, 207-223.e10. https://doi.org/10.1016/j.neuron.2018.12.006 (2019).

61. Numahara, T., Tanemura, M., Nakagawa, T. \& Takaiwa, T. Spatial data analysis by epidermal Langerhans cells reveals an elegant system. J. Dermatol. Sci. 25, 219-228. https://doi.org/10.1016/S0923-1811(00)00129-8 (2001).

62. Hughes, E. G., Kang, S. H., Fukaya, M. \& Bergles, D. E. Oligodendrocyte progenitors balance growth with self-repulsion to achieve homeostasis in the adult brain. Nat. Neurosci. 16, 668-676. https://doi.org/10.1038/nn.3390 (2013).

63. Matthews, B. J. et al. Dendrite self-avoidance is controlled by dscam. Cell 129, 593-604. https://doi.org/10.1016/j.cell.2007.04.013 (2007).

64. Smith, C. J., Watson, J. D., VanHoven, M. K., Colón-Ramos, D. A. \& Miller, D. M. Netrin (UNC-6) mediates dendritic selfavoidance. Nat. Neurosci. 15, 731-737. https://doi.org/10.1038/nn.3065 (2012).

65. Kay, J. N., Chu, M. W. \& Sanes, J. R. MEGF10 and MEGF11 mediate homotypic interactions required for mosaic spacing of retinal neurons. Nature 483, 465-469. https://doi.org/10.1038/nature10877 (2012).

\section{Acknowledgements}

This work is financially supported by JSPS KAKENHI (Grant Nos. 20H03427 to Kenzo Hirose, and 20H02875 to Daisuke Asanuma). The authors would like to thank Dr Shuji Ishihara (University of Tokyo) for discussions and comments, and Dr Tristan Qingyun Li (Washington University School of Medicine) for providing clustering data of scRNASeq, and Enago (www.enago.jp) for the English language review. 


\section{Author contributions}

Y.E. and T.M. conceived the organ culture experiments and mathematical modeling and wrote the manuscript, D.A., S. N. and K.H. helped ATPOS-related experiments, A.U. helped the retina culture experiment, Y.K. provided immunohistochemistry data of retina microglia. K.S. helped scRNASeq data analysis. All authors reviewed the manuscript.

\section{Competing interests}

The authors declare no competing interests.

\section{Additional information}

Supplementary Information The online version contains supplementary material available at https://doi.org/ 10.1038/s41598-021-01820-3.

Correspondence and requests for materials should be addressed to T.M.

Reprints and permissions information is available at www.nature.com/reprints.

Publisher's note Springer Nature remains neutral with regard to jurisdictional claims in published maps and institutional affiliations.

(c) (i) Open Access This article is licensed under a Creative Commons Attribution 4.0 International License, which permits use, sharing, adaptation, distribution and reproduction in any medium or format, as long as you give appropriate credit to the original author(s) and the source, provide a link to the Creative Commons licence, and indicate if changes were made. The images or other third party material in this article are included in the article's Creative Commons licence, unless indicated otherwise in a credit line to the material. If material is not included in the article's Creative Commons licence and your intended use is not permitted by statutory regulation or exceeds the permitted use, you will need to obtain permission directly from the copyright holder. To view a copy of this licence, visit http://creativecommons.org/licenses/by/4.0/.

(c) The Author(s) 2021 